\title{
Imunogenética das uveítes
}

\author{
Imunogenetics in the uveites
}

\author{
Cynthia Azeredo Cordeiro ${ }^{1}$ \\ Paula Rocha Moreira ${ }^{2}$ \\ Walderez Ornelas Dutra ${ }^{3}$ \\ Wesley Ribeiro Campos ${ }^{4}$ \\ Antônio Lúcio Teixeira ${ }^{5}$ \\ Fernando Oréfice $^{6}$
}

\section{RESUMO}

Citocinas são moléculas envolvidas na comunicação intercelular nas respostas inflamatória e imune, desempenhando papel relevante nas uveítes. Polimorfismos dos genes responsáveis pela produção de determinadas citocinas têm sido relacionados com a ocorrência e a gravidade de algumas uveítes. Portanto, o presente trabalho tem como objetivo relatar essas possíveis associações, salientando o aspecto individual genético no prognóstico das uveítes.

Descritores: Uveíte/etiologia; Polimorfismo genético; Citocinas; Paraparesia tropical espástica; Infecções por HTLV-I; Antígenos HLA/imunologia; Oftalmopatias/genética; Prognósico

\section{INTRODUÇÃO}

A resposta imune, responsável pela defesa do organismo, é determinada pela interação entre moléculas (citocinas, complexo HLA) e células (monócitos, linfócitos) do sistema imune. Alterações nos níveis dessas moléculas podem interferir na resposta imune, oferecendo maior proteção ou susceptibilidade a diversas doenças inflamatórias e infecciosas ${ }^{(1)}$.

Alterações genéticas podem estar associadas a um grau de maior ou menor produção dessas moléculas, ou ainda interferir em sua fisiologia. Algumas mutações genéticas podem ser suficientemente graves para ocasionar doenças, enquanto outras podem ser silenciosas ou gerar mudanças sutis ou subclínicas. Entre estas, destacam-se os polimorfismos genéticos que podem ser definidos como a troca de um nucleotídeo (adenina - A, guanina - $\mathrm{G}$, timina - $\mathrm{T}$ e citosina - C) por outro em determinado local de um gene (locus), cuja freqüência na população geral é superior a $1 \%{ }^{(2)}$.

A maioria dos estudos buscando associações imunogenéticas com as uveítes foi realizada com os genes dos loci do complexo de moléculas do antígeno leucocitário humano (HLA), do inglês "human leukocyte antigen". Essas moléculas são responsáveis pela apresentação de antígenos aos linfócitos, células responsáveis pelo desencadeamento da resposta imune ${ }^{(1)}$.

Os genes do sistema HLA apresentam diversos polimorfismos, sendo que alguns deles ${ }^{(3)}$ estão associados a maior susceptibilidade a várias doenças, inclusive oftalmológicas. A tabela 1 apresenta uveítes associadas com polimorfismos de determinadas moléculas $\mathrm{HLA}^{(3-6)}$.

As citocinas são proteínas que promovem a interação entre as células do sistema imune, exercendo efeitos sobre o crescimento, a motilidade, a diferenciação ou a função das células-alvo (Tabela 2). A partir de estudos experimentais realizados principalmente em camundongos, as citocinas foram classificadas em citocinas inflamatórias (por exemplo, IL-1, TNF $\alpha$ ), envolvidas na inflamação; citocinas de perfil Th1 (por exemplo, IFN $\gamma$ ), que medeiam resposta imune celular, e citocinas de perfil Th2 (por exemplo, IL4, 
IL-6, IL-10), que inibem a resposta Th1, tem efeito antiinflamatório e participam de resposta imune humoral ${ }^{(1)}$. Em humanos, a IL-10 é uma citocina produzida tanto por células Th1 como Th2, que possui um importante papel antiinflamatório. Outras subpopulações de células T CD4+, como as Th3, T regulatórias e Th17 também já foram descritas e desempenham funções imunoregulatórias, baseadas nas citocinas produzidas por elas ${ }^{(1)}$.

Embora o mecanismo patogênico exato de várias uveítes seja desconhecido, observa-se o envolvimento de diferentes citocinas no processo ${ }^{(7)}$. Assim, polimorfismos que resultem em aumento da produção de citocinas inflamatórias ou diminuição da produção de citocinas antiinflamatórias na ocorrência de uveíte podem predispor a uma maior inflamação intra-ocular ${ }^{(2)}$.

O objetivo do presente trabalho é revisar sistematicamente os estudos de associação de determinados polimorfismos

\begin{tabular}{|ll|}
\hline Tabela 1. Uveítes & $\begin{array}{c}\text { associadas a polimorfismos do sistema HLA } \\
\text { (Human Leukocyte Antigen) }\end{array}$ \\
Uveíte & HLA \\
Síndrome da histoplasmose & HLA-DR2, HLA-DQ6, HLA-DR15, \\
ocular presumida & HLA-B7 \\
Pars planite & HLA-DR2, HLA-DR15, HLA-DR17, \\
& HLA-DRB1, HLA-DQA1, \\
& HLA-DQB1 \\
Uveíte associada a ARJ & HLA-DRB1, HLA-B27 \\
Doença de Behçet & HLA-B51 \\
Coriorretinopatia de Birdshot & HLA-A29 \\
Uveíte anterior & HLA-B27, HLA-B51, HLA-DQA1, \\
& HLA-DQB1, HLA-DRB1 \\
TINU & HLA-DQ, HLA-DR \\
Síndrome de & HLA-DRB1, HLA-DQB1, \\
Vogt-Koyanagi-Harada & HLA-DQA1 \\
Oftalmia simpática & HLA-CW, HLA-DRB1, \\
& HLA-DQA1 \\
ARJ= artrite reumatóide juvenil; TINU= nefrite tubulo-intersticial e uveíte \\
\hline
\end{tabular}

dos genes das citocinas com a ocorrência e/ou gravidade de diferentes uveítes.

\section{Uveite por HTLV-1}

O vírus linfotrópico humano tipo 1 (HTLV-1) está associado à leucemia/linfoma de células $\mathrm{T}$ do adulto, paraparesia espástica tropical/mielopatia (TSP/HAM) e uveíte (HU), embora a grande maioria dos indivíduos infectados pelo HTLV-1 sejam assintomáticos ${ }^{(8)}$.

Clinicamente, a uveíte associada ao HTLV-1 (HU) é caracterizada por moderada a grave infiltração celular ocular e moderada vasculite retiniana ${ }^{(9)}$. Foi demonstrado que quantidades significativas de várias citocinas, incluindo TNF $\alpha$, são produzidas no humor aquoso de pacientes portadores de $\mathrm{HU}^{(10)}$. Paralelamente, estudos demonstraram que indivíduos que apresentem polimorfismos nas posições $-238,-308,-863$ e -1031 do gene produtor de TNF $\alpha$ produzem maiores níveis dessa citocina na resposta imune frente a diferentes estímulos ${ }^{(11-12)}$.

A partir disso, realizou-se um estudo investigando a distribuição de cinco polimorfismos do gene produtor do TNF $\alpha$ $(-1031,-863,-857,-308$ e -238) em pacientes portadores de HU, portadores assintomáticos e controles saudáveis. A freqüência de polimorfismos nas posições -1031T/C e -863C/A foi maior nos pacientes portadores de $\mathrm{HU}$, sendo estatisticamente distinta em relação aos controles. Esses resultados sugerem que os polimorfismos do gene do TNF $\alpha$ nessas posições podem constituir fator de risco para a ocorrência de $\mathrm{HU}^{(11)}$.

\section{Uveíte intermediária idiopática}

Uveíte intermediária é uma inflamação intra-ocular que envolve vítreo anterior, retina periférica e pars plana. Acomete com maior frequiência indivíduos de 5 a 30 anos de idade, sem preferência por gênero. A etiologia é desconhecida, mas existem várias doenças associadas, como neurite óptica idiopática, esclerose múltipla, doenças inflamatórias intestinais, linfoma, sarcoidose, doenças tireoidianas, além de várias doen-

\begin{tabular}{|c|c|c|}
\hline Citocinas & Efeitos celulares e sistêmicos & Poliformismo associado (locus) \\
\hline Fator de necrose tumoral (TNF) & $\begin{array}{l}\text { Ativação de células endoteliais e neutrófilos; } \\
\text { apoptose de muitos tipos celulares; } \\
\text { febre; síntese de proteínas de fase } \\
\text { aguda; catabolismo muscular e de gordura. }\end{array}$ & $\begin{array}{l}\text { Uveíte associada ao HTLV-I (-1031 e -868) } \\
\text { Uveíte anterior }(-857,-308 \text { e -238) }\end{array}$ \\
\hline Interferon (INF) & $\begin{array}{l}\text { Estado antiviral e expressão de MHC de } \\
\text { classe I aumentada } \\
\text { em todas células; ativação de células NK. }\end{array}$ & Uveíte intermediária (-874) \\
\hline Interleucina-1 (IL-1) & $\begin{array}{l}\text { Ativação de células endoteliais; } \\
\text { febre e síntese de proteínas } \\
\text { de fase aguda. }\end{array}$ & Uveíte anterior( IL-1ra +2018) \\
\hline Interleucina-10 (IL-10) & $\begin{array}{l}\text { Inibição da produção de IL-12; expressão de co- } \\
\text { estimuladores e moléculas MHC da classe linos } \\
\text { macrófagos e células dendríticas. }\end{array}$ & $\begin{array}{l}\text { Uveíte intermediária }(-1082) \\
\text { Oftalmia simpática }(-1082,-819 \text { e -592) }\end{array}$ \\
\hline MCP-1 (CCL2) & Recrutamento misto de leucócitos & Uveíte anterior $(-63555,-2518)$ \\
\hline Fractalcina (CX3CL1) & Ativação leucocitária e proteção neuronal & Vasculite retiniana $(-839$ e -745$)$ \\
\hline CTLA-4 & Sinalização inibitória do linfócito $T$ & Doença de Behçet (-49) \\
\hline
\end{tabular}


ças infecciosas, como as causadas por vírus Epstein-Baar, HIV, HTLV-1, hepatite C, doença de Whipple, doença de Lyme, doença da arranhadura do gato, toxocaríase, tuberculose e sífilis ${ }^{(13)}$.

Estabeleceu-se que a produção de IFN $\gamma$ na presença do alelo $-874 \mathrm{~T}$ apresenta-se aumentada ${ }^{(14)}$. O polimorfismo de IL-10, citocina antiinflamatória, nas posições -1082, -819 e -592 está associado com baixa produção da citocina ${ }^{(15)}$.

Realizou-se, então, um estudo em pacientes portadores de uveíte intermediária idiopática e controles saudáveis, investigando a distribuição dos polimorfismos dos genes de IL-10 (-1082G/A e -819C/T) e IFN $\gamma$ (-874T/A). Foi observada maior freqüência do alelo $-874 \mathrm{~T}$ do gene do IFN $\gamma$ em pacientes do que em controles e do genótipo IL-10 -1082AA em pacientes com maior gravidade da doença. Além disso, constatou-se maior gravidade em pacientes que tinham o genótipo IFN $\gamma$ -874TA ou TT combinado com o genótipo IL-10 -1082AA. Esses resultados sugerem que a gravidade da doença pode ser parcialmente determinada por uma interação entre os genes das citocinas baseados na baixa produção de IL-10 e na alta produção de $\operatorname{IFN} \gamma^{(16)}$.

\section{Oftalmia simpática}

Oftalmia simpática é uma uveíte bilateral granulomatosa que ocorre após trauma penetrante em um olho (olho "excitante") que resultará, futuramente, em uma resposta inflamatória no olho contralateral (olho "simpatizante")(4).

Em um estudo realizado em pacientes com diagnóstico de oftalmia simpática e em controles saudáveis, investigou-se a distribuição do polimorfismo dos genes produtores de IL-10 (-1082G/A, -819C/T e -592C/A). Associações estatisticamente significativas foram observadas entre os polimorfismos do gene de IL-10 na posição -1082G/A e a recorrência da doença, definida como aumento da atividade da doença com piora da acuidade visual ou do exame biomicroscópico após dois meses de estabilidade do quadro com terapia de manutenção com corticosteróides. Além disso, o complexo IL-10 (-1082G, -819C e -592C) foi encontrado como fator protetor contra a recorrência da doença. Esses resultados indicam que os polimorfismos do gene da IL-10 podem constituir marcador de gravidade da doença. Foi estudada também a distribuição de polimorfismos dos genes de TNF $\alpha$ (-308G/A e -238G/A), TNF $\beta$ (1/2G/A), receptor tipo 2 de TNF (+196R/M) e CLTA-4 (+49G/A) entre pacientes e controles, mas não foram encontradas associações significativas com a doença ${ }^{(17)}$.

\section{Uveíte anterior}

Uveíte anterior é a forma mais comum de uveíte. Pode apresentar-se como uveíte anterior idiopática, síndrome de Fuchs, uveíte anterior associada ao HLA-B27, síndrome de Posner-Schlossman e associada a doenças sistêmicas como espondilite anquilosante, síndrome de Reiter, artrite psoriática, doenças inflamatórias intestinais, sarcoidose, artrite reumatóide juvenil, doença de Behçet, sífilis ${ }^{(4)}$.
Além da clássica associação entre o HLA-B27 e uveíte anterior, outros estudos foram realizados na busca de fatores genéticos que estivessem envolvidos na patogênese da doença.

Um estudo foi realizado em pacientes com uveíte anterior associada ao HLA-B27 e controles saudáveis, HLA-B27 positivos e negativos, avaliando a distribuição de polimorfismos do gene do TNF $\alpha$ (-857C/T, -308G/A e -238G/A). A freqüência dos genótipos TNF $\alpha$-308GA e -238GA foram significativamente menores em pacientes com uveíte anterior associada ao HLA-B27, quando comparados com controles HLA-B27 negativos, sugerindo um efeito protetor desses polimorfismos. Quando comparados com controles HLA-B27 positivos, uma menor frequiência do genótipo TNF $\alpha$-238GA foi observada entre os pacientes. Nenhuma diferença nas freqüências foi observada entre os diferentes grupos com relação ao polimorfismo do $\mathrm{TNF} \alpha-857 \mathrm{C} / \mathrm{T}^{(12)}$.

Outro estudo procurou determinar a associação entre polimorfismos dos genes do TNF $\alpha(-1031 \mathrm{~T} / \mathrm{C},-863 \mathrm{C} / \mathrm{A},-857 \mathrm{C} / \mathrm{T}$, -308G/A e -238G/A), linfotoxina $\alpha /$ LTA $(+720,+365$ e +249), receptores de TNF- $\alpha$ : TNFRSF1A $(-201,-230,-845,-839$ e -1135) e TNFRSF1B (+1663, +1668 +1690 e +676) e uveíte anterior aguda, além da possível associação com o HLA-B27 e/ou com o desenvolvimento de complicações. Foi observada maior freqüência do alelo TNF $\alpha-857 \mathrm{~T}$ em pacientes com uveíte anterior aguda quando comparados com controles saudáveis. Em uma análise de subgrupo, observou-se que o desenvolvimento de complicações foi significativamente maior nos pacientes com HLA-B27 positivo que apresentavam os alelos TNFRSF1A -201T e-1135T. A partir desses resultados, sugere-se que variações genéticas no gene do $\mathrm{TNF} \alpha$ e de seus receptores influenciam na susceptibilidade e na gravidade da resposta inflamatória intra-ocular durante o desenvolvimento de um episódio de uveíte anterior aguda. Não foram observadas associações com os polimorfismos TNFo (-1031T/C, -863C/A, -308G/A e -238G/A), linfotoxina $\alpha /$ LTA $(+720,+365$ e $+249)$ e receptores de TNF- $\alpha$ : TNFRSF1A (-230, -845 e -839)e TNFRSF1B $(+1663,+1668+1690 \mathrm{e}+676)^{(18)}$.

Estudo em modelo animal demonstrou que injeção do antagonista do receptor de IL-1 (IL1-ra) diminui a resposta inflamatória intra-ocular em uveíte anterior induzida por injeção intravítrea de IL-1 ${ }^{(19)}$. O polimorfismo do gene da IL-1ra tem sido relacionado com maior susceptibilidade e/ou gravidade de doenças auto-imunes ${ }^{(20)}$. Dessa forma, realizou-se um trabalho em que se encontrou maior frequiência do alelo IL-1ra +2018T nos pacientes com uveíte anterior crônica em comparação com os quadros de uveíte recorrente, e do alelo TNF $\alpha$ -308G em pacientes com uveíte anterior associada ao HLAB27. Foram pesquisadas ainda associações dos polimorfismos dos genes das citocinas IL-6 (-174), IL-10 (-1082), TNF (-238 e -308) com ocorrência, curso e complicações da uveíte anterior, que foram negativas ${ }^{(21)}$.

A quimiocina MCP-1 (CCL2), citocina envolvida no recrutamento de células mononucleares, já foi detectada em concentrações elevadas no humor aquoso de pacientes porta- 
dores de uveíte anterior aguda ${ }^{(22)}$. Além disso, o polimorfismo do gene da MCP-1 na posição -2518 foi relacionado com expressivo aumento da produção dessa quimiocina ${ }^{(23)}$.

Assim, foi investigada a distribuição desse polimorfismo $(-2518 \mathrm{~A} / \mathrm{G})$ nos portadores de uveíte anterior aguda com HLA-B27 positivo. O alelo -2518G foi significativamente mais freqüente nos pacientes do que nos controles também positivos para o HLA-B27. Esse estudo indica papel do polimorfismo do gene MCP-1 (-2518A/G) na ocorrência de uveíte anterior aguda em portadores de HLA-B27 positivo ${ }^{(24)}$.

Nessa linha de investigação, estudou-se também a associação entre polimorfismos dos genes das quimiocinas IL-8 (-37511C/T e 36849C/T), MCP-1 (-62534A/T, -63997C/T e $-63555 \mathrm{~A} / \mathrm{T})$ e seus respectivos receptores IL-8-ra (-4205G/A, $6694 \mathrm{C} / \mathrm{G}, 10188 \mathrm{~T} / \mathrm{C})$ e CCR2 (-50490T/A,$-49776 \mathrm{C} / \mathrm{G}$, $-49715 \mathrm{~A} / \mathrm{G},-49652 \mathrm{~T} / \mathrm{C},-49105 \mathrm{~A} / \mathrm{G},-46295 \mathrm{G} / \mathrm{A} \mathrm{e}-39353 \mathrm{~A} / \mathrm{G})$ e a ocorrência de uveíte anterior aguda idiopática. Observouse que a freqüência do alelo MCP-1 63555T foi significativamente maior no grupo controle, quando comparado com o grupo de pacientes, indicando que o alelo MCP-1 63555T seria um fator protetor contra a ocorrência da doença ${ }^{25)}$. Este estudo corrobora a hipótese de participação do MCP-1 na ocorrência de uveíte anterior aguda ${ }^{(24-25)}$. Os outros polimorfismos não apresentaram associação com a presença e/ou gravidade da doença ${ }^{(25)}$.

\section{Vasculite retiniana idiopática}

Vasculite retiniana é uma inflamação intra-ocular que afeta vasos retinianos. Pode ocorrer como uma condição isolada, como uma manifestação de doenças infecciosas (sífilis, tuberculose) ou neoplásicas, ou em associação com doenças inflamatórias sistêmicas (doença de Behçet, sarcoidose) ${ }^{(26)}$.

A quimiocina CX3CL1 (fractalcina), implicada na adesão leucocitária, já foi observada em tecido uveal, sugerindo seu envolvimento na vigilância imune dos tecidos oculares ${ }^{(27)}$.

Recentes estudos demonstraram que polimorfismos do gene do receptor dessa quimiocina nas posições -839 e -745 estariam relacionados com diminuição da atividade desse receptor ${ }^{(28)}$.

A partir disso, realizou-se um estudo para investigar a distribuição de polimorfismos do gene da CX3CR1 (-745G/A e $-839 \mathrm{C} / \mathrm{T}$ ) em indivíduos portadores de vasculite retiniana idiopática e controles saudáveis. Observou-se uma maior frequiência entre os pacientes do alelo -839T e do complexo -745A e -839T. Sugere-se, então, que os polimorfismos que diminuem a atividade funcional do receptor da quimiocina CX3CL1, desempenham um papel na patogênese da vasculite retiniana idiopática $^{(29)}$.

\section{Doença de Behçet}

A doença de Behçet é uma vasculite sistêmica que tem como manifestação clássica a presença de úlceras mucocutâneas recorrentes, sendo ulceração oral geralmente o primeiro sintoma. Outras manifestações incluem úlceras genitais, lesões cutâneas, alterações vasculares, neurológicas, articulares e oculares. A doença pode afetar o segmento anterior e/ou posterior do olho, levando a ocorrência de iridociclite, hipópio, vitreíte, vasculite e oclusão retiniana, hiperemia do disco óptico e edema macular ${ }^{(30)}$.

Estudos demonstraram a associação entre a doença de Behçet e o HLA-B51. No entanto, a presença do HLA-B51 não é suficiente para explicar a manifestação da doença, levando à busca de outros genes relacionados ${ }^{(4)}$. Como o aumento dos níveis séricos de citocinas pró-inflamatórias tem sido relacionado com maior atividade da doença de Behçet, estudos investigaram a associação de diversos polimorfismos dos genes de citocinas e a doença (TNF $\alpha$, IL-1) $)^{(31-32)}$.

Nos pacientes com envolvimento ocular, observou-se maior frequiência do alelo CTLA-4 -49A e do genótipo CTLA-4 -49AA, quando comparados a pacientes sem envolvimento ocular ${ }^{(33)}$. CTLA-4 é uma molécula sinalizadora expressa na superfície das células $\mathrm{T}$, cuja função principal é inibir a ativação de células $\mathrm{T}^{(1)}$. O polimorfismo do gene da CTLA-4 na posição -49 ocasiona redução de sua função inibitória $^{(34)}$. Portanto, uma menor capacidade de inibição de células $\mathrm{T}$ geneticamente determinada estaria relacionada com o desenvolvimento de doença de Behçet ocular.

A maioria dos estudos que buscam fatores imunogenéticos envolvidos na patogênese das uveítes investigou a associação com o sistema HLA. A evidência do envolvimento das citocinas na patogênese das uveítes sugere alteração de sua produção, levando a busca de associações dos polimorfismos dos genes produtores dessas moléculas com a ocorrência e/ou gravidade das uveítes. Esses estudos contribuem para o entendimento da etiopatogenia e da fisiopatologia das uveítes.

Foram observadas associações de polimorfismos dos genes de citocinas com uveíte por HTLV-1, uveíte intermediária idiopática, oftalmia simpática, uveíte anterior, vasculite retiniana idiopática e acometimento ocular na doença de Behçet.

Como perspectivas futuras, seria interessante investigar o papel desses polimorfismos de genes de resposta imune na patogênese de uveítes infecciosas, especialmente a retinocoroidite toxoplásmica, uveíte posterior mais comum em diversos países e, notadamente, no Brasil. Esses estudos permitirão a identificação de possíveis grupos de risco, possibilitando intervenções clínicas precoces.

\section{ABSTRACT}

Cytokines are molecules involved in intercellular communication in immune and inflammatory responses, playing an important role in uveitis. Genetic polymorphisms responsible for the production of certain cytokines have been associated with the occurrence and the severity of uveitis. Therefore, the present study has the purpose of describing these possible associations, pointing out the individual genetic background in the prognosis of uveitis. 
Keywords: Uveitis/etiology; Polymorphism, genetic; Cytokines; Paraparesis, tropical spastic; HTLV-I infections; HLA antigens/immunology; Eye diseases/genetics; Prognosis

\section{REFERÊNCIAS}

1. Abbas AK, Lichtman AH. Imunologia celular e molecular. $5^{\underline{a}}$ ed. Rio de Janeiro: Elsevier; c2005. p.579.

2. Nussbaum RL McInes RR, Willard HF. Thompson \& Thompson genetics in medicine. $6^{\text {th }}$ ed. Philadelphia: Saunders; c2001. 444p.

3. Alves C, Meyer I, Toralles MB, Marback RL. Associação do sistema de histocompatibilidade humano com doenças oftalmológicas. Arq Bras Oftalmol. 2006;69(2):273-8.

4. Oréfice F. Uveíte: clínica e cirúrgica: texto e atlas. $2^{\underline{a}}$ ed. Rio de Janeiro: Cultura Médica; c2005. p.1484.

5. Martin TM, Rosenbaum JT. Genetics in uveitis. Int Ophthalmol Clin. 2005; 45(2):15-30.

6. Davey MP, Rosenbaum JT. The human leukocyte antigen complex and chronic ocular inflammatory disorders. Am J Ophthalmol. 2000;129(2):235-43.

7. Takase H, Futagami Y, Yoshida T, Kamoi K, Sugita S, Imai Y, et al. Cytokine profile in aqueous humor and sera of patients with infectious or noninfectious uveitis. Invest Ophthalmol Vis Sci. 2006;47(4):1557-61.

8. Uchiyama T. Human T cell leukemia virus type I (HTLV-I) and human diseases. Annu Rev Immunol. 1997;15:15-37.

9. Mochizuki M, Ono A, Ikeda E, Hikita N, Watanabe T, Yamaguchi K, et al. HTLV-I uveitis. J Acquir Immune Defic Syndr Hum Retrovirol. 1996; 13(Suppl 1):S50-6.

10. Sagawa K, Mochizuki M, Masuoka K, Katagiri K, Katayama T, Maeda T, et al. Immunopathological mechanisms of human $\mathrm{T}$ cell lymphotropic virus type 1 (HTLV-I) uveitis. Detection of HTLV-I-infected T cells in the eye and their constitutive cytokine production. J Clin Invest. 1995;95(2): 852-8.

11. Seki N, Yamaguchi K, Yamada A, Kamizono S, Sugita S, Taguchi C, et al. Polymorphism of the 5'-flanking region of the tumor necrosis factor (TNF)alpha gene and susceptibility to human T-cell lymphotropic virus type I (HTLV-I) uveitis. J Infect Dis. 1999;180(3):880-3.

12. El-Shabrawi Y, Wegscheider BJ, Weger M, Renner W, Posch U, Ulrich S, et al. Polymorphisms within the tumor necrosis factor- $\alpha$ promoter region in patients with HLA-B27-associated uveitis association with susceptibility and clinical manifestations. Ophthalmology. 2006;113(4):695-700.

13. Bonfioli AA, Damico FM, Curi AL, Orefice F. Intermediate uveitis. Semin Ophthalmol. 2005;20(3):147-54.

14. Pravica V, Asderakis A, Perrey C, Hajeer A, Sinnott PJ, Hutchinson IV. In vitro production of IFN-gamma correlates with CA repeat polymorphism in the human IFN-gamma gene. Eur J Immunogenet. 1999;26(1):1-3.

15. Turner DM, Williams DM, Sankaran D, Lazarus M, Sinnott PJ, Hutchinson IV. An investigation of polymorphism in the interleukin-10 gene promoter. Eur J Immunogenet. 1997;24(1):1-8.

16. Stanford MR, Vaughan RW, Kondeatis E, Chen Y, Edelsten CE, Graham $\mathrm{EM}$, et al. Are cytokine gene polymorphisms associated with outcome in patients with idiopathic intermediate uveitis in the United Kingdom? $\mathrm{Br} \mathrm{J}$ Ophthalmol. 2005;89(8):1013-6.

17. Atan D, Turner SJ, Kilmartin DJ, Forrester JV, Bidwell J, Dick AD, et al. Cytokine gene polymorphism in sympathetic ophthalmia. Invest Ophthalmol Vis Sci. 2005;46(11):4245-50.

18. Kuo NW, Lympany PA, Menezo V, Lagan AL, John S, Yeo TK, et al. TNF857T, a genetic risk marker for acute anterior uveitis. Invest Ophthalmol Vis Sci. 2005;46(5):1565-71.

19. Rosenbaum JT, Boney RS. Use of a soluble interleukin-1 receptor to inhibit ocular inflammation. Curr Eye Res. 1991;10(12):1137-9.

20. Vijgen L, Van Gysel M, Rector A, Thoelen I, Esters N, Ceelen T, et al. Interleukin-1 receptor antagonist VNTR-polymorphism in inflammatory bowel disease. Genes Immun. 2002;3(7):400-6.

21. Menezo V, Bond SK, Towler, Kuo NW, Baharlo B, Wilson AG, et al. Cytokine gene polymorphisms involved in chronicity and complications of anterior uveitis. Cytokine. 2006;35(3-4):200-6.

22. Verma MJ, Lloyd A, Rager H, Strieter R, Kunkel S, Taub D, et al. Chemokines in acute anterior uveitis. Curr Eye Res. 1997;16(12):1202-8.

23. Rovin BH, Lu L, Saxena R. A novel polymorphism in the MCP-1 gene regulatory region that influences MCP-1 expression. Biochem Biophys Res Commun. 1999;259(2):344-8.

24. Wegscheider BJ, Weger M, Renner W, Posch U, Ulrich S, Hermann J, et al. Role of the CCL2/MCP-1 -2518A $>$ G gene polymorphism in HLA-B27 associated uveitis. Mol Vis. 2005;11:896-900.

25. Yeo TK, Ahad MA, Kuo NW, Spagnolo P, Menezo V, Lympany P, et al. Chemokine gene polymorphisms in idiopathic anterior uveitis. Cytokine. 2006;35(1-2):29-35.

26. Abu El-Asrar AM, Herbort CP, Tabbara KF. Retinal vasculitis. Ocul Immunol Inflamm. 2005;13(6):415-33.

27. Silverman MD, Zamora DO, Pan Y, Texeira PV, Baek SH, Planck SR, et al. Constitutive and inflammatory mediator-regulated fractalkine expression in human ocular tissues and cultured cells. Invest Ophthalmol Vis Sci. 2003; 44(4):1608-15.

28. Faure S, Meyer L, Costagliola D, Vaneensberghe C, Genin E, Autran B, et al. Rapid progression to AIDS in HIV+ individuals with a structural variant of the chemokine receptor CX3CR1. Science. 2000;287(5461):2274-7. Comment on: Science. 2000;290(5499):2031.

29. Wallace GR, Vaughan RW, Kondeatis E, Mathew R, Chen Y, Graham EM, et al. A CX3CR1 genotype associated with retinal vasculitis in patients in the United Kingdom. Invest Ophthalmol Vis Sci. 2006;47(7):2966-70.

30. Bonfioli AA, Orefice F. Behcet's disease. Semin Ophthalmol. 2005;20(3): 199-206.

31. Ahmad T, Wallace GR, James T, Neville M, Bunce M, Mulcahy-Hawes K, et al. Mapping the HLA association in Behcet's disease: a role for tumor necrosis factor polymorphisms? Arthritis Rheum. 2003;48(3):807-13.

32. Karasneh J, Hajeer AH, Barrett J, Ollier WE, Thornhill M, Gul A. Association of specific interleukin 1 gene cluster polymorphisms with increased susceptibility for Behcet's disease. Rheumatology (Oxford). 2003;42(7):860-4.

33. Sallakci N, Bacanli A, Coskun M, Yavuzer U, Alpsoy E, Yegin O. CTLA4 gene 49A/G polymorphism in Turkish patients with Behcet's disease. Clin Exp Dermatol. 2005;30(5):546-50.

34. Ligers A, Teleshova N, Masterman T, Huang WX, Hillert J. CTLA-4 gene expression is influenced by promoter and exon 1 polymorphisms. Genes Immun. 2001;2(3):145-52. 